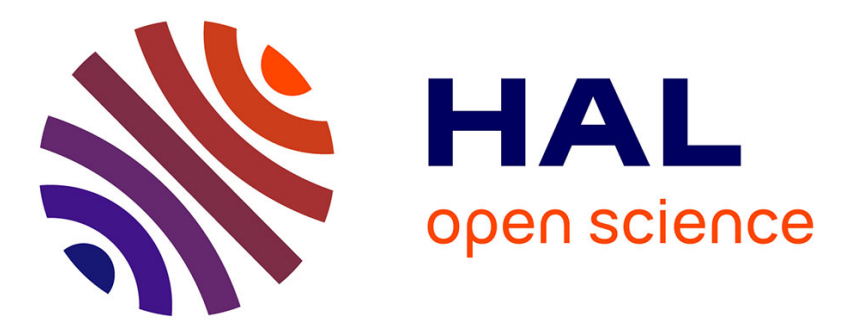

\title{
Studies on kinase-controiled state transitions in Photosystem II and $b \_6 f$ mutants from Chlamydomonas reinhardtii which lack quinone-binding proteins
}

Francis-André Wollman, Claire Lemaire

\section{To cite this version:}

Francis-André Wollman, Claire Lemaire. Studies on kinase-controiled state transitions in Photosystem II and $b \_6 f$ mutants from Chlamydomonas reinhardtii which lack quinone-binding proteins. Biochimica biophysica acta (BBA) - Bioenergetics, 1988, 993 (1), pp.85-94. 10.1016/00052728(88)90058-8 . cea-02931671

\section{HAL Id: cea-02931671 https://hal-cea.archives-ouvertes.fr/cea-02931671}

Submitted on 7 Sep 2020

HAL is a multi-disciplinary open access archive for the deposit and dissemination of scientific research documents, whether they are published or not. The documents may come from teaching and research institutions in France or abroad, or from public or private research centers.
L'archive ouverte pluridisciplinaire HAL, est destinée au dépôt et à la diffusion de documents scientifiques de niveau recherche, publiés ou non, émanant des établissements d'enseignement et de recherche français ou étrangers, des laboratoires publics ou privés. 
Elsevier

BBA 42730

\title{
Studies on kinase-controlled state transitions in Photosystem II and $b_{6} f$ mutants from Chlamydomonas reinhardtii which lack quinone-binding proteins
}

\author{
Francis-André Wollman and Claire Lemaire \\ Service de Photosynthèse, Institut de Biologie Physico-Chimique, Paris (France)
}

(Received 7 July 1987)

(Revised manuscript received 22 October 1987)

Key words: LHC-kinase; $b_{6} f$ complex; State 1-State 2 transition; Plastoquinone pool, oxidized/reduced;

(C. reinhardtii)

\begin{abstract}
We have studied kinase-dependent state transitions in vivo using photosynthetic mutants from the green alga Chlamydomonas reinhardtii lacking in quinone-binding proteins. The aim of our study was to identify proteins involved in the plastoquinone-dependent activation of the LHC-kinase. Whereas mutants totally devoid of the quinone-binding subunits D1 and D2 of Photosystem II showed unaltered state transitions, mutants lacking the $b_{6} f$ complexes were incapable of state transitions. These mutants were blocked in State 1 , which is indicative of either the absence of the LHC-kinase responsible for the regulation, or of the loss of a component responsible for the activation of this enzyme. These two hypotheses are discussed in light of (i) the patterns of phosphorylation of the thylakoid membrane proteins observed in the $b_{6} f$ mutants and (ii) the characteristics of the kinase activities recovered from their thylakoids.
\end{abstract}

\section{Introduction}

Since the first report that state transitions in higher plants were associated with a reversible phosphorylation of some of the LHC subunits [1], several kinases have been identified and purified from spinach thylakoid membranes [2-5]. The LHC-kinase activity in higher plants as well as in

\footnotetext{
Abbreviations: LHC, light-harvesting chlorophyll $a b$ protein complex; PS, Photosystem; CF, coupling factor; PQ, plastoquinone; $F_{\max }$, maximal fluorescence level; PC, plastocyanin; Fe-S, iron-sulfur centre; TMBZ, 3,3,5,5'-tetramethylbenzidine; DBMIB， 2,5-dibromo-3-methyl-6-isopropyl-p-benzoquinone; PMSF, phenylmethylsulphonyl fluoride; NQNO, 2-n-nonyl-4hydroxyquinoline $N$-oxide; DNP-INT, dinitrophenyl ether iodonitrothymol; Hepes, 4-(2-hydroxyethyl)-1-piperazineethanesulphonic acid.

Correspondence: F.A. Wollman, Service de Photosynthèse, Institut de Biologie Physico-Chimique, 13 rue Pierre et Marie Curie, 75005 Paris, France.
}

green algae has been reported to be regulated in situ by the redox state of the plastoquinones $[1,6]$ which carry electron transport from Photosystem II to cytochrome $b_{6} f$ complexes in the photosynthetic electron transfer chain. The molecular mechanism by which this regulation process occurs remains largely unknown and no plastoquinone-dependent activity has as yet been reported for any of the thylakoid kinases that have been purified.

A possible association between a kinase and an integral membrane protein containing plastoquinone-binding sites, with different affinities depending on the redox state of the molecule, would elicit an interaction between a kinase catalytic site and this regulation site. We investigated this possibility using photosynthetic mutants from the green algae Chlamydomonas reinhardtii, lacking in either of the quinone-binding proteins identified so far in the thylakoid membranes. These include PS II mutants totally devoid of the 
quinone-binding subunits D1 or D2 $[7,8]$ and mutants lacking in cytochrome $b_{6} f$ complexes [9].

A preliminary report of this work has been published in Ref. 10.

\section{Material and Methods}

Wild-type and mutant strains of $C$. reinhardtii were grown in Tris-acetate/phosphate medium under continuous illumination $(300 \mathrm{~lx})$ using cool fluorescent light.

The F34 mutant lacks the PS II centres but still shows membrane insertion of D1 and D2 polypeptides [11]; FUD7 and FUD47 mutants lack the PS II centres and are totally devoid of D1 and D2 polypeptides, respectively [7,8]. F18 and FUD4 mutants lack cytochrome $b_{6} f$ complexes [9]. ac21 and ac208 mutants lack the Rieske protein and plastocyanin, respectively $[12,13]$.

ac21F34 and ac208F34 double mutants were obtained by crossing the corresponding nuclear single mutants according to Ref. 14. Tetrads were dissected and double mutant clones, screened by fluorescence as PS II mutants [15], were selected out of nonparental ditype tetrads. FUD7F18 double mutant was obtained by crossing the FUD7 chloroplast mutant, $\mathrm{mt}^{+}$, by the F18 nuclear mutant, $\mathrm{mt}^{-}$. Double mutants were selected after checking cytochrome deficiencies - by TMBZ staining after gel electrophoresis [16] - in whole cells taken from the four clones of a tetrad with a PS II-deficient phenotype.

A typical experiment devised to compare the amount of ${ }^{32} \mathrm{P}$ incorporated in thylakoid polypeptides from cells having a plastoquinone pool oxidized (analogous to state 1) or reduced (analogous to state 2) was as follows: $200 \mathrm{ml}$ of cells in midexponential phase $\left(3 \cdot 10^{6}\right.$ cells $\left./ \mathrm{ml}\right)$ were resuspended in Tris-acetate at a chlorophyll concentration of $25 \mu \mathrm{g} / \mathrm{ml}$ and incubated in dim light for $120 \mathrm{~min}$ in the presence of ${ }^{32} \mathrm{P}(200 \mu \mathrm{Ci} / \mu \mathrm{mol})$ at $1 \mu \mathrm{Ci} / \mathrm{ml}$. Cells were then washed in $5 \mathrm{mM}$ Hepes $/ 0.3 \mathrm{M}$ sucrose $/ 10 \mathrm{mM}$ EDTA and resuspended in the same buffer at a chlorophyll concentration of $50 \mu \mathrm{g} / \mathrm{ml}$. Half of the sample was placed in the anaerobic state by an incubation in a tightly capped vessel in the presence of $2 \mathrm{mg} / \mathrm{ml}$ glucose oxidase and $20 \mathrm{mM}$ glucose. The other half was placed in a large flask under strong agitation in order to maximize the air/liquid medium interface. These anaerobic and aerobic treatments were performed in the dark for $40 \mathrm{~min}$. Cells were then rapidly broken in a pre-cooled French press at $35 \mathrm{MPa}$ in the presence of $10 \mathrm{mM}$ $\mathrm{NaF}$ and $200 \mu \mathrm{M}$ PMSF. Thylakoid membrane preparations, gel electrophoresis and autoradiography were then performed as previously described [6].

Fluorescence induction experiments at room temperature were performed as previously described [17] using intact cells pretreated as for ${ }^{32}$ P-labelling experiments, at a concentration of $0.4 A_{680 \mathrm{~nm}}$.

Stationary labelling of whole cells was performed under $300 \mathrm{~lx}$ illumination by adding $\left[{ }^{14} \mathrm{C}\right]$ acetate $(1 \mu \mathrm{Ci} / \mathrm{ml})$ to cultures at $10^{4}$ cells $/ \mathrm{ml}$. Cultures were harvested after seven cell divisions $\left(2 \cdot 10^{6}\right.$ cells $\left./ \mathrm{ml}\right)$ and processed for thylakoid purification.

For $K_{\mathrm{m}}$ determination, purified thylakoid membranes $(200 \mu \mathrm{g}$ chlorophyll $/ \mathrm{ml})$ were resuspended in a reaction mixture containing $20 \mathrm{mM}$ Hepes ( $\mathrm{pH} 7.5) / 0.1 \mathrm{M}$ sucrose $/ 10 \mathrm{mM} \mathrm{NaCl} / 10$ $\mathrm{mM} \quad \mathrm{MgCl}_{2} / 2.5-500 \mu \mathrm{M} \quad\left[\tau_{-}{ }^{32}\right] \mathrm{ATP} \quad(50$ $\mu \mathrm{Ci} / \mu \mathrm{mol})$. The reaction was continued for $2 \mathrm{~min}$ in the light at room temperature. The incubation time was chosen in the time-range of linear ${ }^{32} \mathrm{P}$ incorporation in the thylakoid membranes. The reaction was terminated by a 10 -fold dilution with a chilled $\mathrm{Mg}^{2+}$-depleted Hepes buffer containing $10 \mathrm{mM} \mathrm{NaF}$ and $2 \mathrm{mM}$ unlabelled ATP. After centrifugation, the membrane pellet was washed twice in the same buffer, resuspended in a small volume of Hepes buffer ( $500 \mu \mathrm{g}$ chlorophyll $/ \mathrm{ml}$ ) and Cerenkov radioactivity was counted.

Preparation of kinase-enriched fractions was performed using a modification of the procedure for $\mathrm{CF}_{1} \mathrm{CF}_{0}$ extraction developed by Pick and Racker [18] which we have already applied to the preparation of $b_{6} f$ complexes [9]. After octylglucoside/cholate membrane solubilization and ammonium sulphate fractionation of the crude extract, the $37 \%-48 \%$ fraction was subjected to sucrose gradient centrifugation. Gradient fractions $(100 \mu \mathrm{l})$ were then assayed for kinase activity according to Lin et al. [2] in the presence of 100 $\mu \mathrm{M}\left[\tau_{-}{ }^{32} \mathrm{P}\right] \mathrm{ATP}(200 \mathrm{cpm} / \mathrm{pmol})$ using $500 \mu \mathrm{g}$ casein or lysine-rich histone-III as a substrate. 
The cytochrome content in the gradient fractions was estimated spectrophotometrically as previously described [9].

\section{Results}

We first compared the extent of fluorescence quenching induced, at room temperature, by the reduction of the plastoquinone pool in three strains deficient in PS II centres, but showing (F34) or not (FUD7 and FUD47) membrane insertion of either of the two PS II quinone-binding subunits, $\mathrm{D} 1$ and D2. These differences in polypeptide insertion have been described previously $[7,8,11]$. Independent of their content in D1 and D2, these PS II mutants had a lower fluorescence yield in the anaerobic state (Table I, columns 1-3), as expected for cells placed in State 2 [6].

Quinone-binding sites also exist on the $b_{6} f$ complex. Therefore we looked for the redox control of the plastoquinone pool on the fluorescence yield at room temperature in strains lacking this complex. The comparison of the fluorescence yields at $F_{\max }$ under reducing conditions expressed as a function of that in oxidizing conditions in strains having or not the $b_{6} f$ complex are shown in Table I, columns 3-6. The fluorescence decrease at $F_{\max }$ observed in the wild type in anaerobic conditions is not observed in the FUD4 chloroplast mutant lacking the $b_{6} f$ complex. The $F_{\max }$ in the mutant remains at about the same level as it is in aerobic cells in the wild type (see values between brackets in Table I), which is characteristic of State 1. A similar observation arises from the comparison of the fluorescence yields in PS II mutants containing (FUD7) or not containing (FUD7F18) the $b_{6} f$ complex.
The efficiency of reduction of the plastoquinones by the anaerobic treatment in $b_{6} f$ mutants has been assessed previously [21] and causes a small increase at $F_{\max }$ (Table I, columns 4 and 5) due to the lower chemical quenching of the plastoquinones in their reduced form [20]. Thus, independent of the nuclear - in the case of F18 - or chloroplast - in the case of FUD4 origin of the mutation, strains lacking the $b_{6} f$ complex do not display the fluorescence changes at room temperature which were to be expected from State 1-State 2 transitions.

We then looked for a possible absence of LHC phosphorylation in vivo in $b_{6} f$ mutants. The autoradiogram in Fig. 1 clearly shows that a number of thylakoid polypeptides were still phosphorylated in these mutants. The four PS II polypeptides which were phosphorylated in the wild-type cells [21] were still phosphorylated in the FUD4 mutant. These include the $47 \mathrm{kDa}$ apoprotein of CPIV, analogous to the $43 \mathrm{kDa}$ from PS II in higher plants, the quinone-binding polypeptide, D2, and the two small subunits, $\mathrm{L} 5$ and L6, in the $10 \mathrm{kDa}$ region. These four bands were absent, as expected, in the two strains lacking PS II centres, strains FUD7 and FUD7F18. The other labelled bands in the wild type were as previously described [21], four LHC subunits (numbered 10, 1113 and 17 [22]) and a $40 \mathrm{kDa}$ chlorophyll-binding polypeptide, numbered 9, the function of which is unknown. Two of these bands were no longer phosphorylated in the $b_{6} f$ mutants (FUD4 and FUD7F18) and correspond to the two LHC subunits 13 and 17.

The increase in ${ }^{32} \mathrm{P}$-labelling upon reduction of the PQ pool in cells from the wild-type or the FUD7 mutant was no longer observed in the two

TABLE I

$F_{\max }$ IN THE ANAEROBIC STATE (STATE 2) IN STRAINS DEFICIENT IN PS II AND $b_{6} f$ COMPLEXES

$F_{\max }$ is expressed as a function of $F_{\max }(100)$ in the aerobic state (State 1).

\begin{tabular}{|c|c|c|c|c|c|}
\hline \multicolumn{3}{|c|}{-PS II } & \multirow{2}{*}{$\begin{array}{l}\frac{-\mathrm{PS} \text { II }-b_{6} f}{\text { FUD7F18 }} \\
\text { (4) }\end{array}$} & \multirow{2}{*}{$\begin{array}{l}-b_{6} f \\
\text { FUD4 } \\
(5)\end{array}$} & \multirow{2}{*}{$\begin{array}{l}\text { Wild type } \\
\text { (6) }\end{array}$} \\
\hline $\begin{array}{l}\text { F34 } \\
\text { (1) }\end{array}$ & $\begin{array}{l}\text { FUD47 } \\
\text { (2) }\end{array}$ & $\begin{array}{l}\text { FUD7 } \\
\text { (3) }\end{array}$ & & & \\
\hline 54 & 66 & 52 & 108 & 104 & 70 \\
\hline - & - & - & - & $(46 / 48)^{a}$ & $(46.5 / 32.5)^{a}$ \\
\hline
\end{tabular}

\footnotetext{
${ }^{\text {a }} F_{\max }$ values (arbitrary units) in (State 1/State 2) at a cell concentration of $0.4 A_{680 \mathrm{~nm}}$ in wild type and FUD4 strains.
} 


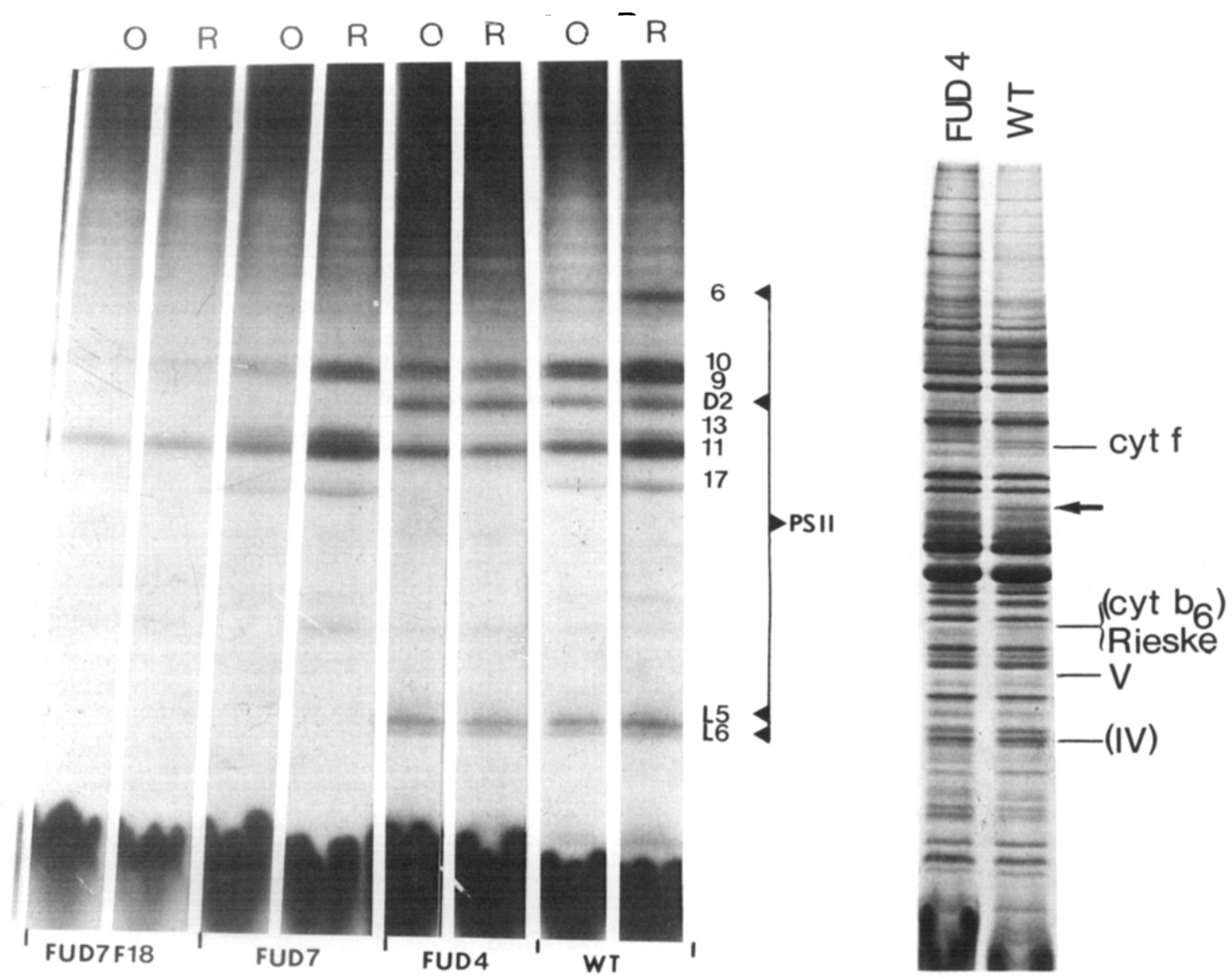

Fig 1 (left) Autoradiogram of thylakoid membranes isolated from ${ }^{32} \mathrm{P}$-labeled cells. $\mathrm{O}$ : aerobic state (oxidizing conditions), analogous to State 1; R: anaerobic state (reducing conditions), analogous to State 2. Note the similar amount of labelling in States 1 and 2 and the absence of phosphorylated bands corresponding to LHC subunits 13 and 17 , in the $b_{6} f$ mutants FUD4 and FUD7F18.

Fig. 2 (right). Autoradiogram of thylakoid polypeptides from ${ }^{14} \mathrm{C}$-labelled cells, viewed after urea-SDS polyacrylamide gel electrophoresis. Note the absence of cytochrome $f$, cytochrome $b_{6}$, the Rieske protein and subunit $V$ in the $b_{6} f$ mutant (FUD4). The arrow indicates an additional polypeptide of about $40 \mathrm{kDa}$ which is absent in the FUD4 strain.

$b_{6} f$ mutants. The amount of labeling remained low under aerobic and anaerobic conditions. This is consistent with a block in State 1 in the latter mutants, as already suggested by their high fluorescence yield at room temperature.

That mutant strains lacking in $b_{6} f$ complexes were blocked in State 1 suggested either an absence of the LHC-kinase or the loss of its activation site.

In Fig. 2 is an autoradiogram of the polypeptide patterns from thylakoid membranes puri- fied from FUD4 and wild-type cells grown in the presence of $\left[{ }^{14} \mathrm{C}\right]$ acetate. Besides the deficiencies in $b_{6} f$ complex subunits previously reported in the FUD4 mutant [9], we noted a deficiency in a 40 kDa polypeptide (arrow on Fig. 2). We were unable to detect this deficiency using conventional staining procedures such as Coomassie blue staining or silver staining. The deficiency in a poor stainable $40 \mathrm{kDa}$ polypeptide in $b_{6} f$ mutants might have been indicative of a possible association between a kinase and $b_{6} f$ complexes. We therefore looked 
for kinase activity in $b_{6} f$ complex preparations. In Fig. 3 are shown the distributions of $b_{6} f$ complexes and kinase activities in the gradient used in the last step of the purification procedure. The fractions showing enrichment in kinase activity stood at lower sucrose density than the $b_{6} f$ complexes. Moreover, kinase activity was still recovered from similar gradient fractions in a preparation using thylakoid membranes from the FUD4 mutant lacking the $b_{6} f$ complex. In both cases the activity with histone-III as a substrate was only $10 \%$ that obtained with casein. The respective kinase activities extracted from the two strains were compared in several ways, using casein as a substrate (Table II); the activity recovered from FUD4 membranes was only $36 \%$ of that recovered from the wild type, on a chlorophyll basis. However this difference had to be corrected for possible variations in the yield of the preparation between the two strains. This was assessed by comparing the relative yields of recovery of $\mathrm{CF}_{1}$ $\mathrm{CF}_{0}$ complexes which were in similar amounts in the starting membranes: the fractions containing the complex were pooled and run on an SDS-gel. We then scanned the Coomassie blue stained bands corresponding to the $\alpha$ and $\beta$ subunits, and observed that the yield of recovery of $\mathrm{CF}_{1}$ was 1.7-times smaller in the FUD4 than in the wildtype preparation. The kinase activity recovered from the FUD4, when corrected by this yield parameter, measured up to $60 \%$ that recovered from the wild type.

Also shown in Table II is a comparison of the specific activities in fractions showing maximal kinase enrichment in the two strains. That from the FUD4 mutant was about $60 \%$ that from the wild type, an estimation which is consistent with the comparison of the total kinase activities extracted from the two strains. We note in Fig. 3 that the distribution of kinase activity in the $b_{6} f$ mutant was shifted slightly toward lower densities as compared to that in the wild type. When compared with the wild-type fraction of same density, the FUD4 fraction with maximal kinase enrichment displayed no significant decrease in specific activity. Therefore, the possibility that one type of kinase only (enriched in fractions 15-19 in the wild type on Fig. 3) would be missing from the FUD4 preparation is consistent with these mea-

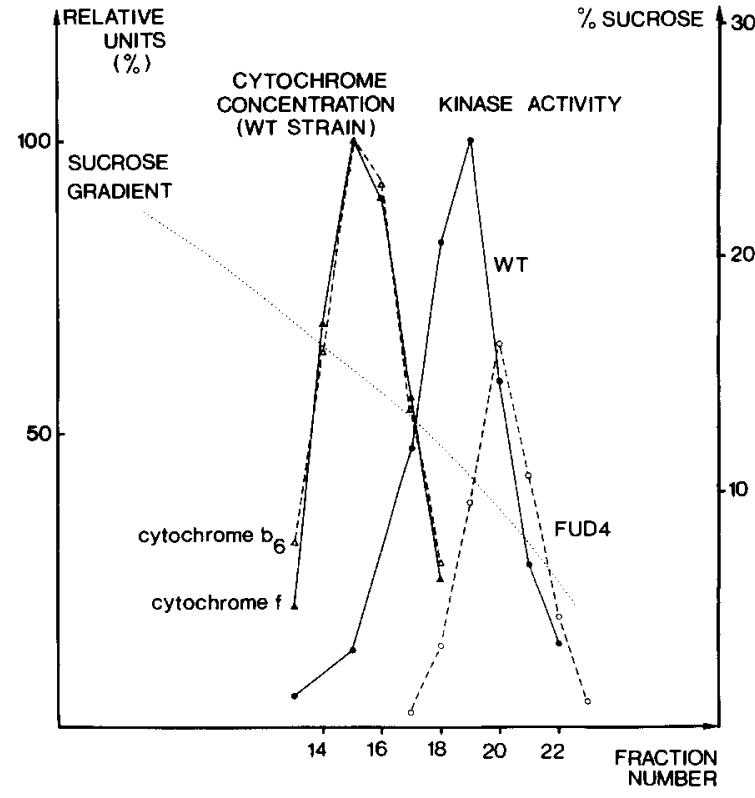

Fig. 3. Distributions of cytochromes $b_{6}$ and $f$ and of kinase activity recovered from a Triton-containing sucrose gradient (dashed lines) using wild-type and FUD4 strains. Kinase activity (relative units) using casein as a substrate, was corrected by a factor of 1.7 in the FUD4 mutant (see text). Note that the distribution of kinase activity is slightly shifted toward lower densities in the FUD4 mutant as compared to the wild-type strain.

TABLE II

COMPARISON OF KINASE ACTIVITIES IN THE FUD4 MUTANT AND IN THE WILD-TYPE STRAIN USING CASEIN AS SUBSTRATE

Specific activity in the FUD4 fraction of maximal activity (fraction 20) was compared with that in the wild type either in the fraction of same density (fraction 20) or in that of maximal specific activity (fraction 19). Total kinase activity is expressed in relative units on a chlorophyll basis. Corrected values take into account the 1.7-fold lower amount of $\alpha$ and $\beta$ subunits of CF1 purified from the FUD4 mutant as compared to that from purified to the wild type using the same purification procedure.

\begin{tabular}{|c|c|c|c|c|}
\hline \multirow[t]{2}{*}{ Strain } & \multicolumn{2}{|c|}{$\begin{array}{l}\text { Specific activity } \\
\text { (pmol } P_{i} \text { transferred/ } \\
\text { mg protein per min) }\end{array}$} & \multicolumn{2}{|c|}{$\begin{array}{l}\text { Kinase activity } \\
\text { mg Chl solubilized } \\
\text { (relative units) }\end{array}$} \\
\hline & max. & fraction 20 & uncorrected & $\overline{\text { corrected }}$ \\
\hline WT & $122(100)^{a}$ & $79(100)^{a}$ & 100 & 100 \\
\hline FUD4 & $69(56)^{a}$ & $69(87)^{a}$ & 36 & 62 \\
\hline
\end{tabular}

a Relative units with respect to the wild-type specific activity (100). 


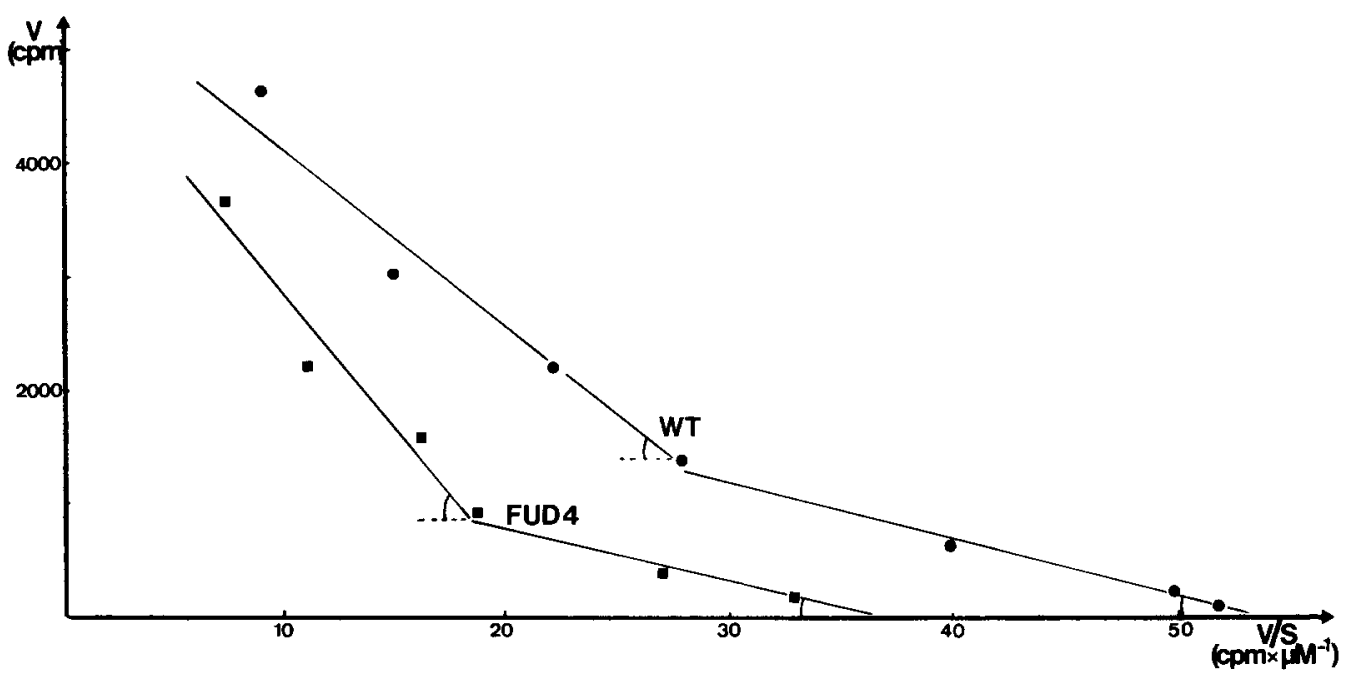

Fig. 4. ${ }^{32} \mathrm{P}$ incorporation (V) in the thylakoid membranes from the wild-type and FUD4 mutant strains, incubated with $2.5-500 \mu \mathrm{M}$ $\left[\tau_{-}^{32}\right.$ P]ATP (S) for $2 \mathrm{~min}$ in the light. Eadie-Hofstee representation. Linear regression analysis elicits computation of two different $K_{\mathrm{m}}$ values for each strain, which are given by the slope of each straight line. $K_{\mathrm{m}}$ values for the wild type: $50 \mu \mathrm{M}$ and $150 \pm 20 \mu \mathrm{M}$. $K_{\mathrm{m}}$ values for the FUD4 mutant: $50 \mu \mathrm{M}$ and $250 \pm 40 \mu \mathrm{M}$.

surements. However, the kinase activities in these fractions were highly unstable, and particularly sensitive to freezing (respective specific activities on a same wild-type sample before and after storage at $-80^{\circ} \mathrm{C}$ were 457 and $122 \mathrm{pmol} \mathrm{P}_{\mathrm{i}} / \mathrm{mg}$ protein per $\min$ ). The $40 \%$ kinase deficiency in the mutant should then be taken as indicative only. The diversity in polypeptide content in the kinase-enriched fractions prevented a reliable attribution of the kinase activity to a particular silver-stained band (gels not shown).

We also studied the $K_{\mathrm{m}}$ for ATP of the total phosphorylation process in the FUD4 and wildtype thylakoid membranes. These experiments were performed using purified thylakoid membranes incubated in the light (PQ pool reduced) with different concentrations of $\left[{ }^{32} \mathrm{P}\right] \mathrm{ATP}$, from 2.5 to $500 \mu \mathrm{M}$, for $2 \mathrm{~min}$. These experimental conditions aimed at activating the LHC-kinase in the wild type so as to produce maximal contrast in kinase activity with that in FUD4. The data plotted as $V$ vs. $V / S$ (Eadie-Hofstee representation) in Fig. 4 indicated more than one phosphorylation process in the thylakoid membranes from the two strains. These data could be fitted by two $K_{m}$ values for ATP in each case. A $50 \mu \mathrm{M} K_{\mathrm{m}}$ was found in the wild-type as well as in the FUD4 thylakoid membranes. Computation of the value of the second $K_{\mathrm{m}}$ was highly dependent on the choice of graphic representation. Nevertheless, a small but significant difference was consistently observed, with the $K_{\mathrm{m}}$ computed for FUD4 mem-

\section{TABLE III}

$F_{\max }$ IN THE ANAEROBIC STATE (STATE 2) IN PS II MUTANTS WITH VARIOUS BLOCKS AT THE $b_{6} f$ LEVEL

$F_{\max }$ is expressed as a function of $F_{\max }(100)$ in the aerobic state (State 1).

\begin{tabular}{|c|c|c|c|c|}
\hline \multicolumn{3}{|l|}{ FUD7 } & \multirow{2}{*}{$\begin{array}{l}\text { ac21F34 } \\
- \text { Fe-S }\end{array}$} & \multirow{2}{*}{$\begin{array}{l}\text { ac208F34 } \\
- \text { PC }\end{array}$} \\
\hline No block & $\mathrm{Q}_{z}$ blocked $^{\mathrm{a}}$ & $\mathrm{Q}_{c}$ blocked $^{\mathrm{b}}$ & & \\
\hline 52 & 50 & 62 & 62 & 62 \\
\hline
\end{tabular}

a Blocked with $30 \mu \mathrm{M}$ DNP-INT.

${ }^{\mathrm{b}}$ Blocked with $2 \mu \mathrm{M}$ NQNO. 


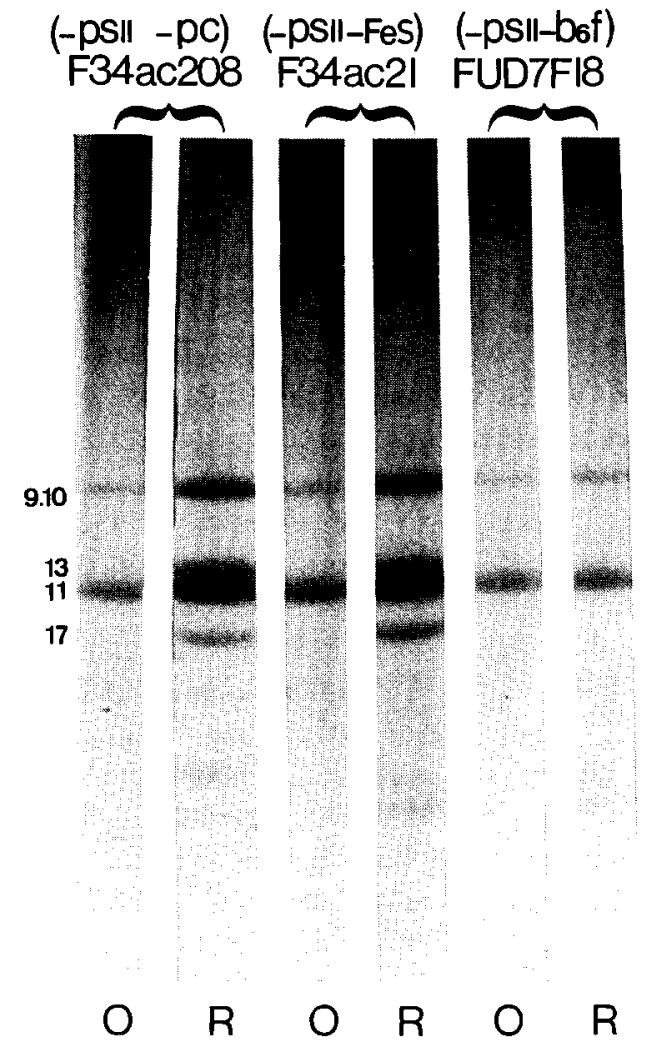

Fig. 5. Autoradiogram of thylakoid membrane polypeptides from ${ }^{32}$ P-labelled cells of PS II mutant strains lacking in either plastocyanin (PC), the Rieske protein ( $\mathrm{FeS})$, or the $b_{6} f$ complex. O: aerobic state (oxidizing conditions) analogous to State 1; R: anaerobic state (reducing conditions) analogous to State 2 .

branes, $250 \pm 40 \mu \mathrm{M}$, being larger than that computed for wild-type membranes, $150 \pm 20 \mu \mathrm{M}$.

We then looked for the possible involvement of the $b_{6} f$ complex in the activation process of the kinase. The subsequent experiments were undertaken on PS II mutants because they yielded larger [6] and more reproducible fluorescence changes upon state transitions than in the wild-type cell. In a first approach, we tried to mimic the absence of either of the two binding sites for plastoquinones on the $b_{6} f$ complexes by using specific inhibitors of each site: DNP-INT for the $Q_{z}$ site [23] and NQNO for the $Q_{c}$ site [24]. Table III shows the result of such an experiment using FUD7 cells. Neither of the two inhibitors blocked state transitions: a $40-50 \%$ decrease in fluorescence yield was observed upon reduction of the PQ pool.
We then investigated the possible involvement of the Rieske protein which is likely to participate in the $\mathrm{Q}_{z}$ site, and that of plastocyanin which binds to the $b_{6} f$ complex. This was examined using mutants lacking in the Rieske protein, as in the F34ac21 strain [12], or lacking in plastocyanin, as in the F34ac208 strain [13]. We observed a quenching in fluorescence (Table III) and an increase in ${ }^{32}$ P-labelling (Fig. 5) in these strains upon aerobic to anaerobic transitions in darkness. These results clearly show that neither of the two proteins was responsible for the block observed in $b_{6} f$-deficient mutants.

\section{Discussion}

The respective abilities of photosynthetic mutants, blocked at different points of the electron transport chain, to perform the kinase-regulated changes in light energy distribution between the two photosystems, were studied in vivo in the green alga, $C$. reinhardtii. This process had to be studied using state transitions that were not to be driven by a photosynthetic electron flow. Therefore we compared aerobic (PQ pool oxidized) versus anaerobic (PQ pool reduced) conditions in darkness. The latter condition has been previously shown to induce State 2 in $C$. reinhardtii in vivo $[6,7]$. State 1 , reached under aerobic conditions in darkness, compared well with that obtained previously by an illumination in the presence of DCMU $[6,7]$, as shown by the amplitude of the changes in LHC phosphorylation and in fluorescence obtained in the present experimental conditions (about 30 and 50\% quenching in State 2 in the wild-type and the F34 mutant, respectively).

Several reports have suggested a specific involvement of PS II centres in the regulation mediated by the LHC-kinase. These included the possibility that PS II centres would either diffuse laterally in association with phosphorylated LHC [25], control LHC movements through electrostatic repulsion due to a phosphorylated PS II component [26], contain a kinase [27] or its activation site on quinone-binding subunits as considered in the present paper. Previous studies using the F34 mutant from $C$. reinhardtii, lacking in PS II centres, gave evidence for an unaltered kinase-mediated regulation process [6,21]: this strain underwent a re- 
versible association of LHC with PS I centres, depending on the phosphorylation state of LHC.

However, the F34 mutant still showed membrane insertion of the quinone-binding PS II subunits, D1 and D2 [11]. These could still be part of the kinase activation process observed in the mutant. The present analysis, showing identical behaviour in the F34 mutant and in two other PS II-deficient strains mutated respectively in the genes of D1 or D2 $[7,8]$ and totally lacking in either of the two polypeptides, demonstrated that PS II has no part in the regulation mediated by the LHC-kinase. In particular, the absence, in such mutants, of the phosphorylated PS II subunits, L5 and L6, which are the probable counterparts of the 9-10 kDa phosphoprotein of PS II from higher plants, argues against the hypothesis of a specific involvement of this PS II subunit in the regulation process [26].

The absence of the $b_{6} f$ complex prevented the occurrence of State 1-State 2 transitions in vivo and greatly modified the phosphorylation pattern of thylakoid membrane polypeptides. These observations could be made irrespective of the presence (FUD4) or absence (F18F34) of PS II centres. We note that two different mutations, leading to the deficiency of the entire set of $b_{6} f$ subunits [9], but located on the nuclear (F18) and plastid (FUD4) chromosomes, respectively, similarly prevented state transitions. This excludes the possibility that this alteration could originate from the genetic background in a particular strain, or from a genetic link between either of the two mutations and another gene involved in the regulation process.

Kinase activity was still detected in the thylakoid membranes of the $b_{6} f$ mutants, although it was no longer regulated by the redox state of the PQ pool. When present, the PS II subunits showed unaltered phosphorylation, as did some of the other phosphoproteins currently observed in the wild-type or in PS II mutants. However, a group of two LHC subunits - polypeptides 13 and 17 - was no longer phosphorylated, whereas another group of polypeptides comprising polypeptide 9 , which is a chlorophyll-binding protein (Bassi, R., personal communication), as well as two other LHC subunits - polypeptides 10 and 11 - still was. The former group was previously shown to undergo phosphorylation changes with kinetics different from those of the latter: only this second group of LHC subunits closely followed the kinetics of the state transitions [21]. The distinct phosphorylation characteristics of these two families of LHC subunits demonstrates a $b_{6} f$-complex-dependent heterogeneity within LHC for the kinase system. This heterogeneity could involve two LHC-kinases with different specificities, a hypothesis which will be discussed below. Alternatively, it could result from a conformational change between two states of the LHC or from two different locations of the complex in the membrane. In these hypotheses, the phosphorylation sites on polypeptides 13 and 17 would be accessible to the kinase only upon an association between LHC and $b_{6} f$ complexes. Such an association has been suggested previously on the basis of the ultrastructural modifications observed in the thylakoid membranes of the $b_{6} f$ mutants [28]. We can rule out the possibility that the extra-membrane segments of polypeptides 13 and 17, which contain the phosphorylation sites and protrude at the outer thylakoid surface in the wild type, were buried in the membrane in the $b_{6} f$ mutants, since their trypsin sensitivity was conserved (not shown). However more subtle conformational changes may have occurred.

The question should then be raised of a possible link between the absence of redox control on the phosphorylation of thylakoid membrane polypeptides in the $b_{6} f$ mutants and the total lack of phosphorylation on polypeptides 13 and $17 . \mathrm{Al}-$ though phosphorylation of these two LHC subunits may be a prerequisite for an increase in phosphorylation of the other phosphopolypeptides in vivo, this is not the case in vitro: we have occasionally observed similar phosphorylation patterns (not labelled bands corresponding to polypeptides 13 and 17) in wild-type thylakoid membranes incubated with $\left[\tau-{ }^{32} \mathrm{P}\right]$ ATP (unpublished observation). However, these membranes still showed reversible phosphorylation of the other LHC subunits in a dark to light transition.

The low level of phosphorylation of the thylakoid membrane polypeptides in $b_{6} f$ mutants was consistent with their high level of fluorescence in reducing conditions, and was indicative of a block in State 1. If the low level of labelling of the 
phosphopolypeptides in the $b_{6} f$ mutants originated from a preexisting irreversible phosphorylation of the LHC subunits - for instance because of the absence of a phosphatase - the mutant cells would be blocked in State 2. Alternatively, enhanced phosphatase activity in the $b_{6} f$ mutants could maintain the cells in State 1. It would not, however, prevent redox-controlled changes in the phosphorylation of the LHC subunits, but would only offset the levels of phosphorylation towards lower values. Contrary to this prediction, LHC phosphorylation in the $b_{6} f$ mutants was not redox-controlled. Therefore, we considered two possible origins of their block in State 1: the absence of an LHC-kinase or the loss of its regulation site.

In the first hypothesis, one should take into account the multiple kinase activities that have been found in thylakoid membranes [3,21,29-32]. Two, maybe three, such enzymes have been purified [2-5]. Therefore, depending on their respective substrate specificities, the absence of the LHC-kinase in $b_{6} f$ mutants could be partly masked by the ability of the other(s) to phosphorylate some LHC subunits. Consistent with the absence of an LHC-kinase would be the slight but significant shift towards lower densities in the distribution of kinase activity among the gradient fractions recovered from the $b_{6} f$ mutant FUD4, as compared to that obtained with the wild type. The somewhat lower total kinase activity extracted from FUD4 thylakoids could also be indicative of a possible deficiency in one type of kinase, but the significance of this observation is severely limited by the variations in the level of kinase activity obtained with the wild type from one experiment to another.

The polypeptide of about $40 \mathrm{kDa}$ lacking in the thylakoid membranes from $b_{6} f$ mutants is a candidate for the particular LHC-kinase that would be missing in these strains. It has about the same molecular weight as CPK2, a putative kinase purified by Lin et al. [2] from spinach thylakoid membranes. The identity of CPK2 was, however, challenged by Coughlan and Hind [5] who attributed this polypeptide to ferredoxin-NADP reductase, an enzyme which may interact as well with $b_{6} f$ complexes.

On the other hand, we noted some difference in our analysis of the $K_{\mathrm{m}}$ values for ATP associated with the total phosphorylation activity in thylakoid membranes from the $b_{6} f$ mutants and from the wild type. However, out of the two $K_{\mathrm{m}}$ values which fitted the data from the two strains, the lower one around $50 \mu \mathrm{M}$ - which is supposedly associated with the LHC-kinase responsible for the regulation $[33,34,4]$ - was unchanged. Therefore, either the LHC-kinase, if missing in the mutant, has a higher $K_{\mathrm{m}}$ for ATP in the 100-150 $\mu \mathrm{M}$ range where we noted a difference between the wild-type and $b_{6} f$ mutants, or it should have a similar $K_{\mathrm{m}}$ - in the $50 \mu \mathrm{M}$ range - as one of the other kinases which remain in the mutants.

An unchanged $50 \mu \mathrm{M} K_{\mathrm{m}}$ is more consistent with an alteration of the activation process in the $b_{6} f$ mutants. This could be due to the loss of the quinone-binding sites, $\mathrm{Q}_{c}$ or $\mathrm{Q}_{z}$, of the $b_{6} f$ complexes. However, inhibitors of quinone binding on the $\mathrm{Q}_{c}$ site, such as NQNO, as well as on the $\mathrm{Q}_{z}$ site, such as DNP-INT, did not alter significantly the fluorescence transitions which accompany the reduction of the PQ pool in thylakoid membranes having a normal $b_{6} f$ complement.

Alternatively, kinase activation could depend on the redox state of an electron carrier, other than the plastoquinones, but associated with the $b_{6} f$ complex. Our experiments showed that neither plastocyanin nor the Rieske protein was part of the regulation process. However the redox carrier, $\mathrm{G}$, which interacts with the $b_{6} f$ complex [35] as well as the two $b$ cytochromes, $b_{\mathrm{h}}$ and $b_{1}$, become reduced upon the aerobic to anaerobic transitions in darkness used in the present study. The midpoint potential of $\mathrm{G}$ and $b_{\mathrm{h}}$ is at about $0 \mathrm{mV}$ $[35,36]$, which is consistent with the titration of kinase activation performed by Horton et al. [37]. In addition, changes in the redox state of these components may still occur via the $\mathrm{Q}_{c}$ site upon illumination of higher plant chloroplasts in the presence of DBMIB, an experiment which has been taken as indicative of the involvement of the PQ pool in the activation process [1].

\section{Acknowledgements}

We are indebted to J. Girard-Bascou for her advice and help in the isolation of double mutants. We thank J. Lavergne, J.-L. Popot and A. Crofts for stimulating discussions. C.L. is supported by 
the Agence Française pour la Maîtrise de l'Energie. This work was supported by the CNRS, U.A.04 1187.

\section{References}

1 Allen, J.F., Bennett, J., Steinback, K.E. and Arntzen, C.J. (1981) Nature 291, 21-25.

2 Lin, Z.F., Lucero, H.A. and Racker, E. (1982) J. Biol. Chem. 257, 12153-12156.

3 Lucero, H.A., Lin, Z.F. and Racker, E. (1982) J. Biol. Chem. 257, 12157-12160.

4 Coughlan, S.J. and Hind, G. (1986) J. Biol. Chem. 261, $11378-11385$.

5 Coughlan, S.J. and Hind, G. (1986) J. Biol. Chem. 261, $14062-14068$.

6 Wollman, F.A. and Delepelaire, P. (1984) J. Cell. Biol. 98, 1-7.

7 Bennoun, P., Spierer-Herz, M., Erickson, J., Girard-Bascou, J., Pierre, Y., Delosme, M. and Rochaix, J.D. (1986) Plant Mol. Biol. 6, 151-160.

8 Erickson, J., Rahire, M., Malnoë, P., Girard-Bascou, J. Pierre, Y., Bennoun, P. and Rochaix, J.D. (1986) EMBO J. $5,1745-1754$.

9 Lemaire, C., Girard-Bascou, J., Wollman, F.A. and Bennoun, P. (1986) Biochim. Biophys. Acta 851, 229-238.

10 Lemaire, C., Girard-Bascou, J. and Wollman, F.A. (1987) in Progress in Photosynthesis Research (Biggins, $\mathbf{J}$., ed.), Vol. IV, pp. 655-658, Martinus Nijhoff, Dordrecht.

11 Delepelaire, P. (1984) EMBO J. 3, 701-706.

12 Levine, R.P. and Smillie, R.M. (1962) Proc. Natl. Acad. Sci. USA 48, 417-421.

13 Gorman, D.S. and Levine, R.P. (1965) Proc. Natl. Acad. Sci. USA 54, 1665-1669.

14 Levine, R.P. and Ebersold, W.T. (1960) Annu. Rev. Microbiol. 14, 197-214.

15 Bennoun, P. (1974) C.R. Acad. Sci. Paris 279, 1915-1917.

16 Thomas, P.E., Ryan, D. and Levin, W. (1976) Anal. Biochem. $75,168-176$.

17 Wollman, F.A. and Diner, B. (1980) Arch. Biochem. Biophys. 201, 646-659.
18 Pick, U. and Racker, E. (1979) J. Biol. Chem. 254, 2793-2799.

19 Bennoun, P. (1983) FEBS Lett. 156, 363-365.

20 Vernotte, C., Etienne, A.L. and Briantais, J.M. (1975) Biochim. Biophys. Acta 545, 519-527.

21 Delepelaire, P. and Wollman, F.A. (1985) Biochim. Biophys. Acta 809, 277-283.

22 Chua, N.H. and Bennoun, P. (1975) Proc. Natl. Acad. Sci. USA 72, 2175-2179.

23 Trebst, A. (1980) Methods Enzymol. 69, 675-715.

24 Jones, R.W. and Whitmarsch, J. (1985) Photobiochem. Photobiophys. 9, 119-127.

25 Barber, J. (1982) Annu. Rev. Plant. Physiol. 33, 261-295.

26 Allen, J.F. and Holmes, N.G. (1986) FEBS Lett. 202, 175-181.

27 Owens, G.C., Wettern, M., Lavintman, N., Ish-Shalom, D., Schuster, G., Kirilousky, D. and Ohad, I. (1982) in Cell Function and Differentiation (Akoyunoglou, G., Evangelopoulos, A.E., Georgatsos, J., Palaiologos, G., Trakatellis, A. and Tsiganos, C.P., eds.), pp. 223-231, Alan R. Liss, New York.

28 Olive, J., Vallon, O., Wollman, F.A., Recouvreur, M. and Bennoun, P. (1986) Biochim. Biophys. Acta 851, 239-248.

29 Millner, P.A., Widger, N.R., Abbott, M.S., Cramer, W.A. and Dilley, R.A. (1982) J. Biol. Chem. 257, 1736-1742.

30 Markwell, J.P., Baker, N.R. and Thornber, J.P. (1983) Photobiochem. Photobiophys. 5, 201-207.

31 Markwell, J.P., Baker, N.R., Bradbury, M. and Thornber, J.P. (1984) Plant Physiol. 74, 348-354.

32 Farchaus, J.D., Dilley, R.A. and Cramer, W.A. (1985) Biochim. Biophys. Acta 809, 17-26.

33 Bennett, J., Steinback, D.E. and Arntzen, C.J. (1980) Proc. Natl. Acad. Sci. USA 77, 5253-5257.

34 Black, M.T., Foyer, C.H. and Horton, P. (1984) Biochim. Biophys. Acta 767, 557-562.

35 Lavergne, J. (1983) Biochim. Biophys. Acta 725, 25-33.

36 Joliot, P. and Joliot, A. (1988) Biochim. Biophys. Acta 933, in press.

37 Horton, P., Allen, J.F., Black, M.T. and Bennett, J. (1981) FEBS Lett. 125, 193-196. 